\title{
Some Effects of Streptomycin on Pseudoperonospora humuli, the Downy Mildew of Hop
}

\author{
By M. J. GRIFFIN* AND J. R. COLEY-SMITH \\ Department of Botany, The University, Hull, HU6 ${ }_{7} R X$
}

(Accepted for publication I4 August 1971)

\begin{abstract}
SUMMAR Y
Two sprays of streptomycin $(1000 \mu \mathrm{g} . / \mathrm{ml}$ ) considerably reduce sporulation of the hop downy mildew fungus, Pseudoperonospora humuli, on leaves of primary systemically infected shoots. Streptomycin markedly inhibited germination of its sporangia in vitro. Toxicity was dependent on sporangial concentration, incubation temperature and the cleanliness of the suspension but was independent of sporangial age. There were no marked differences in sensitivity to streptomycin between sporangia from five different isolates of Ps. humuli. Two commercial formulations of streptomycin were as inhibitory to sporangial germination as pure streptomycin sulphate. Sublethal concentrations of streptomycin interfered with cleavage of sporangial cytoplasm and increased the proportion of multiflagellate zoospores. The proportion of multiflagellate multinucleate zoospores liberated was dependent on streptomycin concentration. Germination of multiflagellate zoospores was observed. Streptomycin was very inhibitory to zoospore germination but had little effect on zoospore motility and germ-tube growth at concentrations which caused a high incidence of cyst lysis. Streptomycin was as toxic to sporangia of Phytophthora infestans as to those of Ps. humuli, whereas sporangia of Plasmopara viticola and Peronospora parasitica were less sensitive to the antibiotic.
\end{abstract}

\section{INTRODUCTION}

Pseudoperonospora humuli (Miy. \& Tak.) Wilson causes one of the few fungal diseases which can be controlled successfully with an antibiotic; however, the precise way in which streptomycin controls hop downy mildew is far from clear. It has been reported that streptomycin exerts both protectant and eradicant properties against Ps. humuli and also reduces sporulation and infectivity of sporangia (Horner \& Maier, I957; Maier, 1959, I960; Coley-Smith \& Beard, 196I; Schicke, 196I; Horner, I963; Coley-Smith \& Royle, I965; Coley-Smith, 1966). Reduced sporulation on streptomycin-sprayed basal spikes is probably the main controlling effect of the antibiotic in the British Isles, and in the first part of this paper this effect has been assessed quantitatively.

Ogawa, McCain \& Hall (1960), unlike other workers in the U.S.A., obtained poor control of Pseudoperonospora humuli with streptomycin. They also determined the effects of streptomycin and several other fungicides on germination of sporangia and zoospores and on zoospore motility. Of the chemicals tested, streptomycin and wettable sulphur were the least toxic. Streptomycin $(200 \mu \mathrm{g}$. $/ \mathrm{ml}$.) only slightly reduced sporangial germination and although zoospore motility was inhibited within $4 \mathrm{~min}$., germination of cysts was apparently not prevented. This paper indicates that streptomycin is far more toxic to germination of sporangia and zoospores than was suggested by the results of Ogawa et al. (1960), and analyses its effects on the stages of germination of sporangia of Ps. humuli.

* Present address: Plant Pathology Department, Agricultural Development and Advisory Service, Wye, Ashford, Kent. 


\section{Hop propagation}

\section{METHODS}

Pseudoperonospora humuli was maintained on plants of the variety Eastwell Golding produced throughout the year from root stocks (vernalized for at least Io weeks at $\mathrm{I}^{\circ}$ ) derived from 2-node soft-wood cuttings. Pot plants were inoculated with downy mildew at the stage when three to four pairs of leaves had fully expanded. A more detailed account of hop propagation is given elsewhere (Griffin, I969).

\section{Maintenance of fungi}

Hop downy mildew. An isolate of Pseudoperonospora humuli originally obtained from the Department of Hop Research, Wye College, Kent, was perpetuated on intact pot plants of Eastwell Golding. Sporangial suspensions were sprayed onto the abaxial surface of the leaves and plants then incubated in polythene bags in a growth-room at $14^{\circ}\left( \pm r^{\circ}\right)$ with a I6 h. photoperiod $(3000 \mathrm{~lx})$. Polythene bags were opened after $20 \mathrm{~h}$., water remaining on leaves allowed to evaporate and the bags then tied again. After incubation for 6 or 7 days, heavily infected leaves were excised and washed in chilled distilled water ( $\mathrm{I}$ to $5^{\circ}$ ) to detach sporangia. Suspensions were filtered through two thicknesses of muslin to remove macroscopic particles, and concentrations (sporangia $/ \mathrm{ml}$.) adjusted after at least io separate haemocytometer counts.

Cabbage downy mildew. The isolate of Peronospora parasitica (Pers. ex Fr.) Fr. was obtained from the National Vegetable Research Station, Wellesbourne, Warwick. Seedlings of Brassica oleracea var. capitata cultivar. Primo were sprayed with a spore suspension of Per. parasitica and incubated in polythene bags in a constant temperature growth-room at $I 8^{\circ}\left( \pm I^{\circ}\right)$ with a $16 \mathrm{~h}$. photoperiod. Six days later infected cotyledons were detached and washed in chilled distilled water to obtain a sporangial suspension.

Grapevine downy mildew. The isolate of Plasmopara viticola (Berk. \& Curt. ex de Bary) Berl. \& de Toni was obtained from I.C.I. Limited, Jealott's Hill Research Station, Bracknell, Berkshire. Two-node soft-wood cuttings of Vitis vinifera var. Black Hamburg were rooted in a mist-propagation unit and grown to a height of about $30 \mathrm{~cm}$. Leaves were sprayed with a sporangial suspension and the plants incubated in polythene bags in a constant temperature growth-room at $18^{\circ}\left( \pm \mathrm{I}^{\circ}\right)$ with a $16 \mathrm{~h}$. photoperiod. After 7 days infected leaves were excised and washed in chilled distilled water to detach sporangia.

Potato blight. Phytophthora infestans (Mont.) de Bary (NI 2 Culture Collection, Department of Botany, University of Hull) was grown on solid frozen-pea medium (Griffin, I969) in Roux bottles. The agar was inoculated with a sporangial suspension and cultures incubated in the dark for 6 days at $20^{\circ}$. Sporangia were harvested in chilled distilled water (I to $2^{\circ}$ ) and suspensions filtered through muslin.

\section{Antibiotic solutions}

Concentrations of streptomycin are expressed in terms of streptomycin base $\left(\mathrm{C}_{21} \mathrm{H}_{39} \mathrm{~N}_{7} \mathrm{O}_{12}\right)$ corrected to maximum theoretical potency $(798 \mu \mathrm{g} . / \mathrm{mg}$.). Streptomycin salts were dissolved in sterile distilled water and short-term storage of antibiotic stock solutions ( $1000 \mu \mathrm{g} . / \mathrm{ml}$.) was at minus $18^{\circ}$.

\section{Spore germination}

Sporangia of Pseudoperonospora humuli normally germinated by liberating from three to eight biflagellate zoospores. The time taken to emerge in water varied from $<\mathrm{I} h$. (at 22 
to $25^{\circ}$ ) to $>15 \mathrm{~h}$. (at I to $3^{\circ}$ ). In the majority of experiments sporangia were incubated at $12^{\circ}$ at which zoospore emergence usually commenced within $2 \mathrm{~h}$. and was complete after $4 \mathrm{~h}$. The final percentage germination of sporangia in distilled water (rarely $<90 \%$ ) was independent of temperature from 5 to $20^{\circ}$ but was usually erratic above $20^{\circ}$ and completely inhibited at 26 to $28^{\circ}$. In dense suspensions the proportion of zoospores which encysted and produced germ tubes was generally $>75 \%$. With suspensions of $<5 \times 10^{4}$ sporangia/ $\mathrm{ml}$, however, germination of zoospores was erratic and usually $<50 \%$; when the density was $<5 \times 10^{3}$ sporangia $/ \mathrm{ml}$. zoospore germination was invariably $<5 \%$ and on occasions complete lysis (= plasmoptysis) was recorded (Griffin, I969). It was not possible therefore to determine accurately the effect of streptomycin on zoospore germination in dilute suspensions.
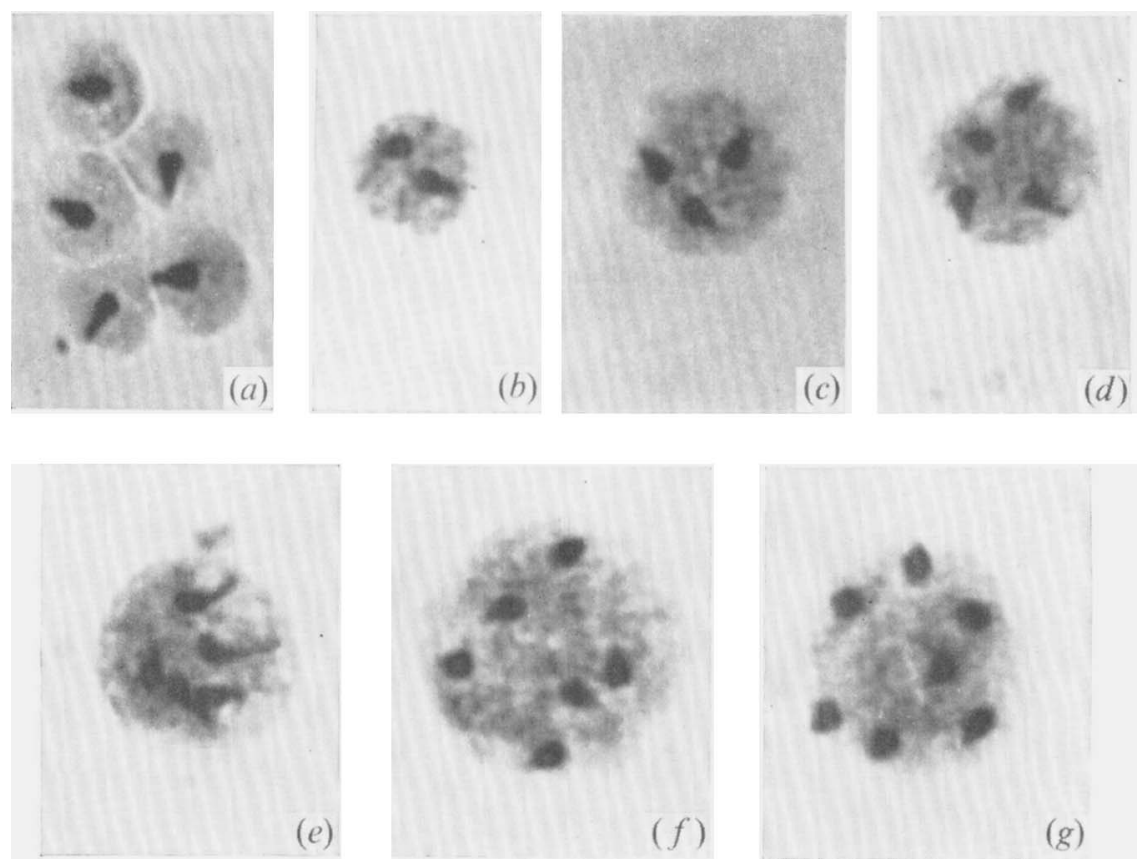

Fig. I. Zoospores of Pseudoperonospora humuli which emerged from sporangia suspended in streptomycin $(25 \mu \mathrm{g} . / \mathrm{ml}$.). (a) to $(g)$ Zoospores (fixed in osmic acid vapour and stained with Ledingham's mixture) with $\mathrm{r}, 2,3,4,5,6$ and 7 nuclei respectively. Magnification approx. $\times 1300$.

\section{Toxicity tests}

Equal volumes of sporangial suspension and streptomycin solution were mixed in $6 \mathrm{ml}$. Pyrex tubes. Samples were removed with Pasteur pipettes and three discrete drops per treatment placed on a glass slide suitably positioned in a moist Petri dish. Distilled water controls were included with all tests. Concentrations of sporangia and antibiotic given in this paper were those in the final test mixture. Since sporangia were harvested in chilled distilled water, the temperatures of suspensions when first placed on the slide were always less than the desired incubation temperature. Percentage germination was assessed by counting at least 500 sporangia, and absence of the papilla was taken as a criterion of germination. Slight variations in $\mathrm{pH}$ of test mixtures and in volume of droplets from a Pasteur pipette had no significant effect on toxicity of streptomycin to sporangia of Pseudoperonospora humuli (Griffin, 1969). 


\section{Examination of zoospores}

Staining technique. Droplets of suspension were placed on glass slides and zoospores fixed by a 60 sec. exposure to vapour arising from a $2 \%(\mathrm{w} / \mathrm{v})$ aqueous osmic acid solution. Droplets were then mixed on the slide with an equal volume of half-strength Ledingham's stain (McLean \& Cook, 1952). Stained zoospores were dried on the slides at $60^{\circ}$ for 30 to $60 \mathrm{~min}$., differentiated in fresh clove oil for 3 to $5 \mathrm{~min}$., passed through three changes of xylene (6o s. each) and mounted in euparal. Flagella and nuclei were stained violet and cytoplasm pinkish red. By careful staining it was possible to differentiate flagella and nucleus (or nuclei) on the one zoospore (Garrett \& Tomlinson, 1967; Griffin, 1969). However, in the process of differentiating for nuclei, flagella were frequently decolourized (Fig. I $a$ to $g$ ).
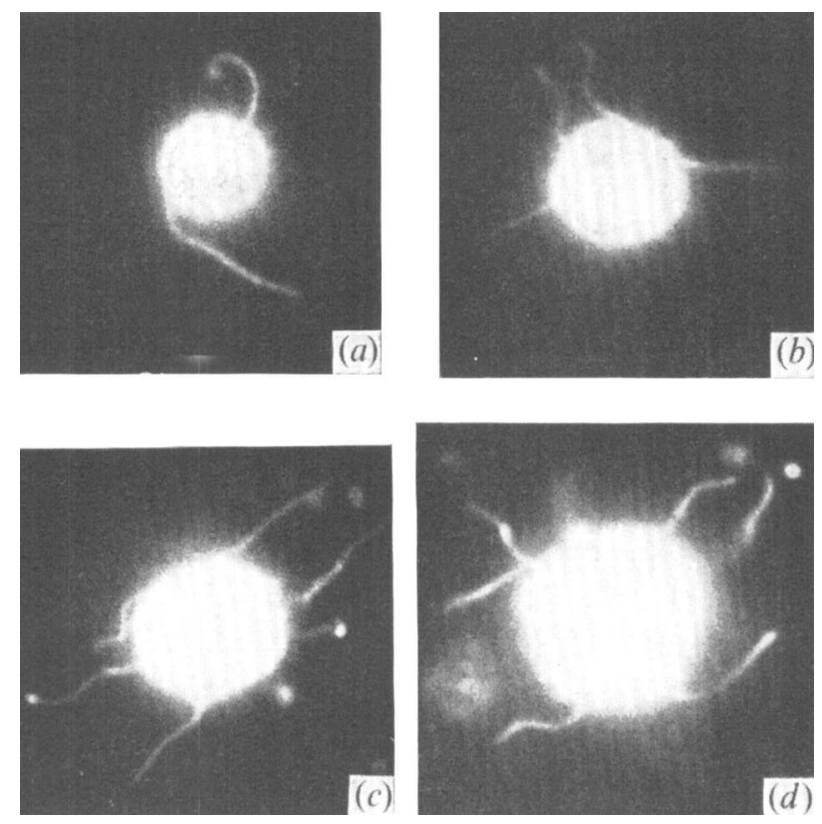

Fig. 2. Zoospores of Pseudoperonospora humuli which emerged from sporangia suspended in streptomycin (25 $\mu \mathrm{g} . / \mathrm{ml}$.). (a) to $(d)$ Zoospores (fixed in glutaraldehyde) with 2, 4, 6 and 8 flagella respectively. Dark field photomicrographs of magnification approx. $\times 850$.

Since a nucleus was invariably associated with two flagella in both uninucleate and multinucleate zoospores of Pseudoperonospora humuli, it was considered that twice the nuclear number equalled the number of flagella. However, Garrett \& Tomlinson (1967) observed a few zoospores of Olpidium brassicae (normally uniflagellate) in which two flagella were associated with a nucleus larger than normal. With zoospores of Ps. humuli, the association of a nucleus with more than two flagella was never observed.

Dark field microscopy. Zoospores were fixed in $2 \%(\mathrm{v} / \mathrm{v})$ aqueous glutaraldehyde in

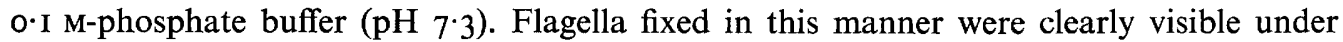
dark-field illumination at magnification $\times 260$ (Fig. $2 a$ to $d$ ). With larger multiflagellate zoospores (8, IO, I 2 and 14 flagella) some flagella were usually obscured (Fig. $2 d$ ). When odd numbers of flagella were observed (particularly 7, 9 and I I) then such zoospores were recorded as having 8 , Io and 12 flagella respectively. 


\section{Statistical analysis}

Figures for percentage germination of sporangia were converted to angles (arcsin transformation) for analysis of variance.

\section{RESULTS}

Effect of streptomycin on sporulation of Pseudoperonospora humuli

Streptomycin sulphate at $1000 \mu \mathrm{g} . / \mathrm{ml}$. in I \% (v/v) aqueous glycerol was sprayed onto newly emerged primary systemically infected shoots of the hop variety Eastwell Golding. At weekly intervals $1 \mathrm{~cm}$. discs of tissue were punched from leaves near the apex of sprayed infected shoots, washed, blotted dry and their sporulation capacity assessed by the microenvironment method of Cruickshank \& Mueller (I957) with a water-water system. The

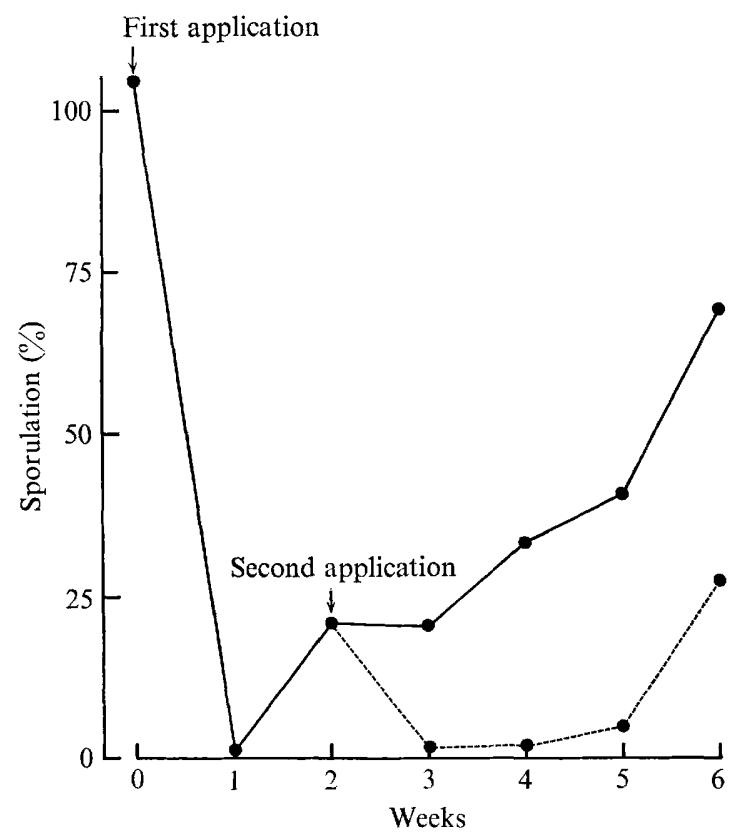

Fig. 3. The effect of streptomycin ( $1000 \mu \mathrm{g}$. base $/ \mathrm{ml}$.) on sporulation of Pseudoperonospora humuli. I application, --- 2 applications of antibiotic. Sporulation on discs from streptomycin-treated shoots was expressed as a percentage of that on untreated controls.

discs (Io per treatment from Io different shoots) were incubated overnight at $20^{\circ}$, dropped in a standard volume of $50 \%(\mathrm{v} / \mathrm{v})$ aqueous ethanol, and the sporangia counted by haemocytometer. A marked effect of antibiotic treatment was apparent (Fig. 3). One week after the first application of streptomycin the sporulation capacity of treated shoots had fallen to near zero but subsequently there was a gradual recovery over the 6-week period. A second application of streptomycin had a similar effect and at the end of the experiment shoots which had received two applications were able to produce only $27.3 \%$ as many sporangia as untreated controls. 


\section{Effect of streptomycin on sporangial germination of Pseudoperonospora humuli}

Dosage response curves. Streptomycin was tested at two incubation temperatures. The results (Table I) clearly show the marked inhibitory effect of streptomycin on sporangial germination. When $\%$ inhibition of germination was plotted against streptomycin concentration, dosage-response curves were usually sigmoid in shape. It is generally considered that variation in resistance to a toxicant among a population of spores, as measured by the logarithm of the threshold toxic dosage, follows the normal distribution pattern (Bliss, 1935; Wilcoxon \& McCallan, I939). When dosage-response curves for streptomycin inhibition of sporangial germination were replotted with logarithmic probability co-ordinates a straight-line relationship was normally obtained (Fig. 4). LD 95 and LD 50 values from the dosage-response curves were 64.5 and $17.1 \mu \mathrm{g}$. $/ \mathrm{ml}$. at $12{ }^{\circ}$ and 23.4 and $9.2 \mu \mathrm{g} . / \mathrm{ml}$. at $18^{\circ}$, showing a pronounced effect of incubation temperature on the sensitivity of sporangia to streptomycin. These results were in marked contrast to those of Ogawa et al. (I960), who with a less dense suspension (incubated at $12^{\circ}$ ) recorded $65 \%$ germination of sporangia in $200 \mu \mathrm{g} . / \mathrm{ml}$. streptomycin.

Table I. The effect of streptomycin on germination of sporangia of Pseudoperonospora humuli

$\%$ Germination in water control: $93^{\circ} \mathrm{I}$ at $\mathrm{I} 2^{\circ}$ and $9 \mathrm{I} \cdot 4$ at $\mathrm{I} 8^{\circ}$; density of suspension: $10^{5}$ sporangia/ $\mathrm{ml}$; incubation time: $20 \mathrm{~h}$.

\begin{tabular}{|c|c|c|c|c|}
\hline \multirow[b]{2}{*}{$\begin{array}{l}\text { Streptomycin } \\
(\mu \mathrm{g} . / \mathrm{ml} .)\end{array}$} & \multicolumn{2}{|c|}{$\begin{array}{c}\text { Inhibition of germination } \dagger \\
(\%)\end{array}$} & \multicolumn{2}{|c|}{$\begin{array}{l}\text { Ungerminated sporangia showing } \\
\text { cytoplasmic breakdown (\%) }\end{array}$} \\
\hline & $12^{\circ}$ & $18^{\circ}$ & $12^{\circ}$ & $18^{\circ}$ \\
\hline 10 & $14 \cdot 6^{*}$ & $58 \cdot \mathrm{I}$ & 63 & 5 \\
\hline 20 & $59^{\circ} 0$ & $92 \cdot 7$ & 86 & 65 \\
\hline 30 & 74.9 & $97 \cdot 7$ & 88 & 78 \\
\hline 40 & $82 \cdot 3$ & $99 \cdot 7$ & 82 & 73 \\
\hline 50 & $92 \cdot 4$ & $99 \cdot 8$ & 82 & 86 \\
\hline 70 & $96 \cdot \mathrm{I}$ & $100 \cdot 0$ & 82 & 77 \\
\hline 100 & $98 \cdot 5$ & $100 \cdot 0$ & 91 & 89 \\
\hline
\end{tabular}

* In all tables in this paper a single asterisk signifies that germination of zoospores was observed.

$\dagger$ Corrected for natural mortality (Bliss, 1935).

Streptomycin had a marked effect on the cytoplasm of sporangia whose germination had been inhibited (Table I). Cytoplasm of normal viable sporangia of Pseudoperonospora humuli appeared fairly smooth and greenish in colour (using bright-field illumination) but in some sporangia after suspension in streptomycin for 6 to $\mathrm{I} 2 \mathrm{~h}$. cytoplasm became darkishbrown, granular and disorganized (Fig. $5 a, b$ ). The proportion of sporangia showing cytoplasmic disruption appeared to be dependent on three interrelated factors; incubation temperature, antibiotic concentration and density of the suspension. Incidence of cytoplasmic breakdown was lower at densities of $10^{5}$ sporangia $/ \mathrm{ml}$. and above in $<25 \mu \mathrm{g}$. streptomycin/ ml. after incubation at $\mathrm{I} 8$ to $25^{\circ}$ (e.g. Table I).

When germination of sporangia was assessed after incubation for $20 \mathrm{~h}$. at $12^{\circ}$ motile zoospores were invariably seen in the water controls and the lower concentrations of streptomycin, whereas in higher concentrations there was usually $100 \%$ lysis. With an increase in antibiotic concentration there was a corresponding decrease in the number of zoospores liberated. Because there was much lysis of zoospores in low density water sus- 


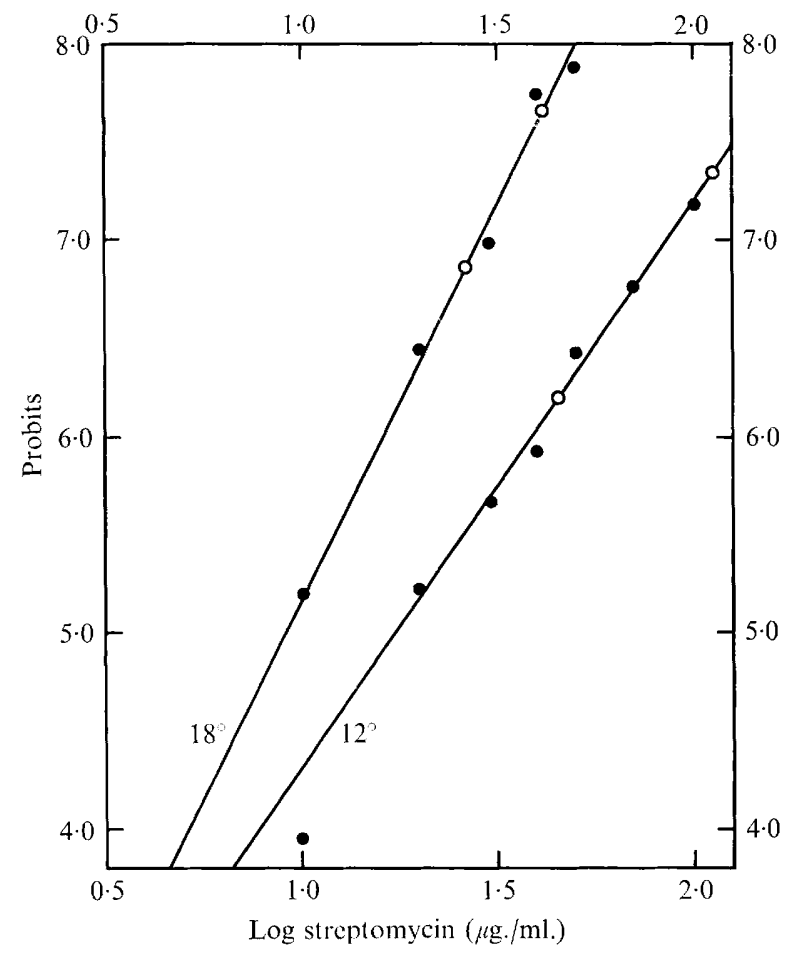

Fig. 4. Sample regression of probits (inhibition of sporangial germination) on log streptomycin concentration at $12^{\circ}$ and $18^{\circ} . \mathrm{O}-\mathrm{O}=$ sample regression line. Conditions were as described for Table $\mathrm{I}$. The point $\mathrm{I} \cdot 00,3.94$ on the $12^{\circ}$ dosage-response curve was discordant with the straight line which was consistent with the other observations and was omitted from calculation of the regression coefficient (Bliss, 1935). Probits for $100 \%$ inhibition are not included in the $18^{\circ}$ curve.
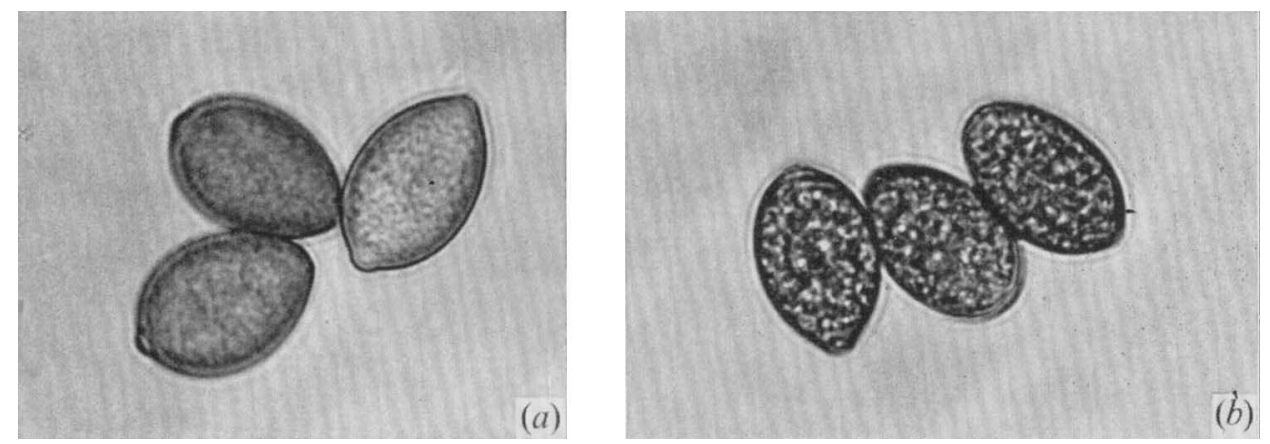

Fig. 5. Bright field photomicrographs of sporangia of Pseudoperonospora humuli both taken using identical optical conditions. Magnification approx. $\times 1000 .(a)$ Viable sporangia in distilled water. (b) Sporangia which had been suspended in streptomycin ( $100 \mu \mathrm{g} . \mathrm{ml}$.) for $6 \mathrm{~h}$. Note the granular appearance of the cytoplasm compared with $(a)$.

pensions (Griffin, 1969) it was considered that the low zoospore concentration sometimes had more effect than the streptomycin itself.

Cleavage of sporangial cytoplasm. The proportion of multinucleate zoospores (two or more nuclei) of Pseudoperonospora humuli liberated in distilled water by three different 
batches of sporangia was determined by fixing zoospores in osmic acid vapour and staining with Ledingham's mixture. More than $98 \%$ of zoospores from each of the three batches of sporangia were uninucleate. The emergence of a small percentage of multiflagellate multinucleate zoospores in water suspensions is not uncommon and has been reported for several fungi: Plasmodiophora brassicae (Kole, 1955), Phytophthora infestans (Boyd, I968), Phytophthora megasperma var. sojae (Ho \& Hickman, 1967) and Olpidium brassicae (Garrett \& Tomlinson, 1967).
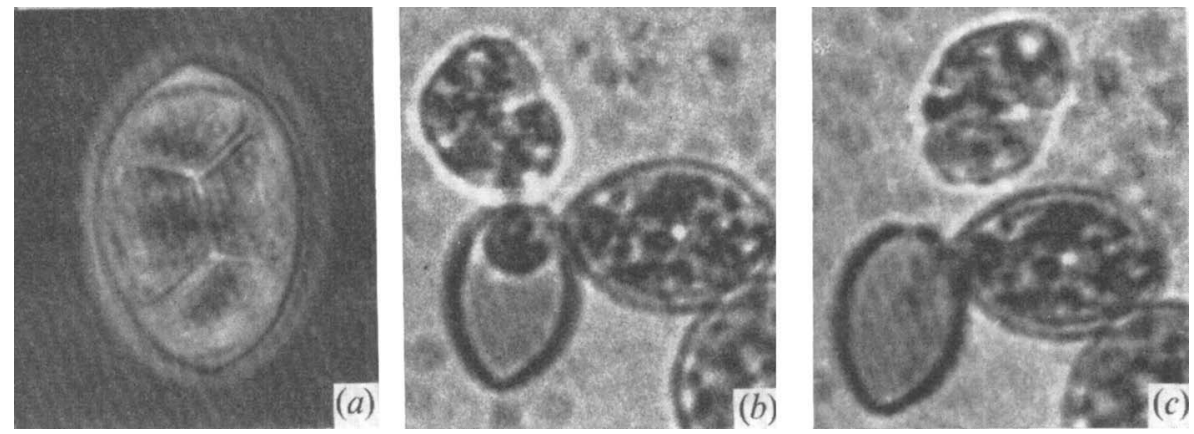

Fig. 6. (a) Sporangium of Pseudoperonospora humuli (fixed in glutaraldehyde) showing cleavage planes in cytoplasm. Phase-contrast photomicrograph of magnification approx. $\times 1300 .(b)$, (c) Stages in the germination of a sporangium of $P$ s. humuli suspended in streptomycin $(25 \mu \mathrm{g} . / \mathrm{ml}$.). Note failure of cytoplasmic cleavage resulting in the liberation of a single multiflagellate zoospore. Bright field cinephotomicrographs of magnification approx. $\times 900$.

Table 2. Liberation of multiflagellate zoospores by sporangia of Pseudoperonospora humuli suspended in different concentrations of streptomycin

Density of suspension: $1 \cdot 5 \times 10^{5}$ sporangia/ml.; incubation: $3 \frac{1}{2} \mathrm{~h}$. at $12^{\circ}$.

\begin{tabular}{|c|c|c|c|c|c|c|c|c|c|}
\hline \multirow{2}{*}{$\begin{array}{l}\text { Strepto- } \\
\text { mycin } \\
(\mu \mathrm{g} . / \mathrm{ml} .)\end{array}$} & \multirow{2}{*}{$\begin{array}{c}\text { Germination } \\
\text { of } \\
\text { sporangia* } \\
(\%)\end{array}$} & \multirow{2}{*}{$\begin{array}{l}\text { Number of } \\
\text { zoospores } \\
\text { examined }\end{array}$} & \multicolumn{5}{|c|}{$\begin{array}{l}\text { Numbers of zoospores } \\
\text { in classes with: }\end{array}$} & & \multirow{2}{*}{$\begin{array}{c}\text { Multiflag- } \\
\text { ellate } \\
\text { zoospores } \\
(\%)\end{array}$} \\
\hline & & & $2 \mathrm{~F} \dagger$ & $4 F$ & $6 \mathrm{~F}$ & $8 \mathrm{~F}$ & IOF & $\mathrm{I} 2 \mathrm{~F}$ & \\
\hline 0 & 73 & 505 & 500 & 5 & 0 & 0 & 0 & 0 & 0.9 \\
\hline 10 & 57 & 635 & 580 & 40 & I I & 3 & I & 0 & $8 \cdot 6$ \\
\hline 25 & 45 & 656 & 509 & 85 & 39 & I 6 & 6 & I & $22 \cdot 4$ \\
\hline 35 & 26 & 382 & 222 & 98 & 47 & I3 & 2 & 0 & $41 \cdot 8$ \\
\hline 50 & 9 & 268 & 89 & I IO & 60 & 6 & 3 & 0 & $66 \cdot 7$ \\
\hline 75 & 7 & 36 & I & 10 & 18 & 6 & I & o & $97 \cdot 2$ \\
\hline 100 & 5 & 20 & 0 & 0 & 5 & 7 & 5 & 3 & $100 \cdot 0$ \\
\hline
\end{tabular}

Streptomycin interfered with the normal cleavage of sporangial cytoplasm (Fig. 6a) causing liberation of a high proportion of multiflagellate multinucleate zoospores (Fig. I $b$ to $g$; Fig. $2 b$ to $d$ ). Emergence (in streptomycin) of the entire cytoplasmic content in the form of a large multiflagellate zoospore was observed on several occasions (Fig. $6 b, c$ ). To quantify this phenomenon, I $\mathrm{ml}$. of suspension was added to an equal volume of streptomycin solution, and when sporangia had germinated zoospores were fixed in glutaraldehyde. A droplet of suspension was removed from each treatment before fixation and sporangial germination recorded (Table 2). Fixed zoospores were examined microscopically with dark-field illumination and the number of flagella per zoospore recorded. 
The ratio of multiflagellate to biflagellate zoospores increased markedly with increase in streptomycin concentration. No biflagellate zoospores were observed in the $100 \mu \mathrm{g}$. streptomycin $/ \mathrm{ml}$. treatment although they were often seen at this concentration in other experiments. Although streptomycin always interfered with cleavage of sporangial cytoplasm, considerable variation in the ratio of multiflagellate to biflagellate zoospores occurred between different batches of sporangia.
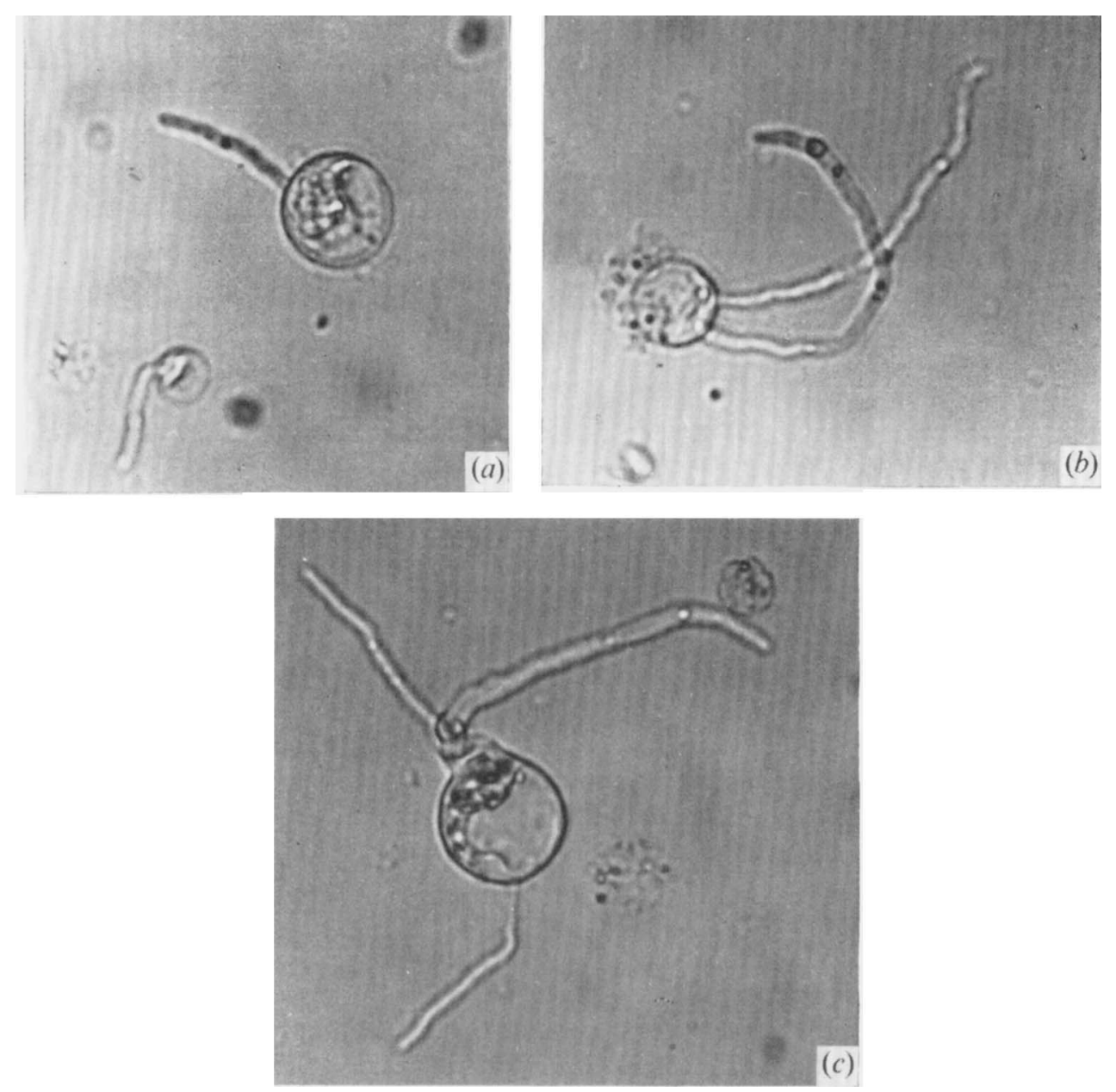

Fig. 7. Germinating zoospores (= cysts) of Pseudoperonospora humuli which emerged from sporangia suspended for $45 \mathrm{~min}$. in streptomycin $(200 \mu \mathrm{g} / \mathrm{ml}$.) and then resuspended in distilled water. Magnification approx. $\times 750 .(a)$ Large multinucleate cyst producing a single germ tube. For comparison, note germination of a typical uninucleate cyst (bottom left). (b), (c) Multinucleate cysts producing two and three germ tubes respectively. Note length of germ tubes compared with the uninucleate cyst in $(a)$. Two lysed zoospores can also be seen in $(c)$.

Multiflagellate zoospores possessed one or more conspicuous vacuoles and their shape was highly variable. Movement of streptomycin-induced multiflagellate zoospores, as with those liberated naturally in distilled water, was erratic giving little indication of co-ordination between pairs of flagella. Regardless of their original shape, multiflagellate zoospores 
eventually rounded-off to form more or less spherical cysts which, unlike those of biflagellate zoospores, were often vacuolated. Multinucleate cysts usually lysed within a few minutes of encysting; larger cysts (four to eight nuclei) appeared to lyse more readily than smaller cysts (two to three nuclei). Usually, onset of the encysting stage was more rapid with multiflagellate than with biflagellate zoospores. Occasionally multinucleate cysts germinated and produced from one to eight (more normally one to four) germ tubes which were considerably longer than those from normal cysts (Fig. $7 a$ to $c$ ). There appeared to be no definite relationship between size of cysts and the number of germ tubes produced. However, no cysts were seen in which the number of germ tubes exceeded the number of nuclei.

Table 3. Duration of motility of Pseudoperonospora humuli zoospores suspended in streptomycin

Density of suspension: $3 \times 10^{5}$ zoospores $/ \mathrm{ml}$; incubation temperature: $12^{\circ}$.

\begin{tabular}{ccccccc}
$\begin{array}{c}\text { Strepto- } \\
\text { mycin } \\
(\mu \mathrm{g} . / \mathrm{ml} .)\end{array}$ & \multicolumn{5}{c}{ Proportion of motile zoospores with respect to the water control } \\
\cline { 2 - 7 } 20 & I h. & $3 \mathrm{~h}$. & $6 \mathrm{~h}$. & I9 h. & $23 \mathrm{~h}$. & $26 \mathrm{~h}$. \\
50 & +++ & ++ & ++ & ++ & ++ & ++ \\
100 & +++ & ++ & ++ & ++ & + & + \\
200 & +++ & ++ & ++ & + & + & 0 \\
300 & ++ & ++ & ++ & 0 & 0 & 0 \\
& ++ & + & + & 0 & 0 & 0
\end{tabular}

+++ , Number of motile zoospores similar to that in the water control; ++ , marked reduction in motile zoospores compared with control; + , isolated motile zoospores; 0 , motile zoospores not observed.

Zoospore motility. An aqueous sporangial suspension was incubated for $3 \mathrm{~h}$. at $12^{\circ}$ to induce emergence of zoospores. One ml. quantities of zoospore suspension were then mixed with equal volumes of streptomycin solution and incubated in $50 \mathrm{ml}$. Pyrex beakers. Drops of suspension were removed at intervals, examined microsopically and the number of motile zoospores estimated (Table 3). Motile zoospores were observed after $6 \mathrm{~h}$. in $200 \mu \mathrm{g}$. antibiotic/ml. and after $23 \mathrm{~h}$. in I00 $\mu \mathrm{g}$. $/ \mathrm{ml}$. In a few experiments (Griffin, I969) there were more motile zoospores (after $20 \mathrm{~h}$. at $12^{\circ}$ ) in the lowest streptomycin concentration than in the water control. The reasons for this are not known. It was concluded that the effects of streptomycin on the energetics of zoospore movement were not nearly so marked as the effects on encystment and germination.

Zoospore germination. Factors affecting the toxicity of streptomycin to zoospore germination were not fully determined, though it appeared that $\%$ germination was dependent on zoospore density and independent of incubation temperature (Griffin, 1969). These tests were complicated by the presence of sporangial cases in the suspension. Nevertheless, it was concluded that germination of zoospores was considerably more sensitive to streptomycin than was germination of sporangia. Results differed markedly from those of Ogawa et al. (1960), who reported that $200 \mu \mathrm{g}$. streptomycin $/ \mathrm{ml}$. failed to stop zoospore germination.

Zoospores suspended in streptomycin solution normally lysed during the period (usually $<30 \mathrm{~min}$. at $\mathrm{I}^{\circ}$ ) after encystment began but before a germ tube appeared. Sudden bursting of actively swimming zoospores was rarely seen. The lengthy motile periods in relatively high concentrations of streptomycin (shown in Table 3) lend support to this observation. When zoospores did germinate in streptomycin no adverse effect of the antibiotic on germtube growth was noticed. Clarke (I966) found that $1000 \mu \mathrm{g}$. streptomycin $/ \mathrm{ml}$. incorporated into a solid medium did not reduce early sporeling growth of Phytophthora infestans whereas 
as little as $10 \mu \mathrm{g} . / \mathrm{ml}$. prevented all post-sporeling growth and colony formation. A similar effect was reported with Phytophthora cactorum (Shaw \& Elliot, 1968).

Factors influencing the toxicity of streptomycin to sporangia of Pseudoperonospora humuli

Age of sporangia. Four hop plants of similar size were selected and sprayed with a sporangial suspension. There was an interval of $24 \mathrm{~h}$. between the inoculation of each plant. Seven days after the first plant was inoculated sporangia were harvested from all plants, the densities of suspensions adjusted and toxicity tests carried out in the normal manner. There was no significant difference in the reaction of sporangia of different ages to streptomycin. Normally, sporangia for routine toxicity tests were not harvested after as little as 4 or 5 days because too few were present.

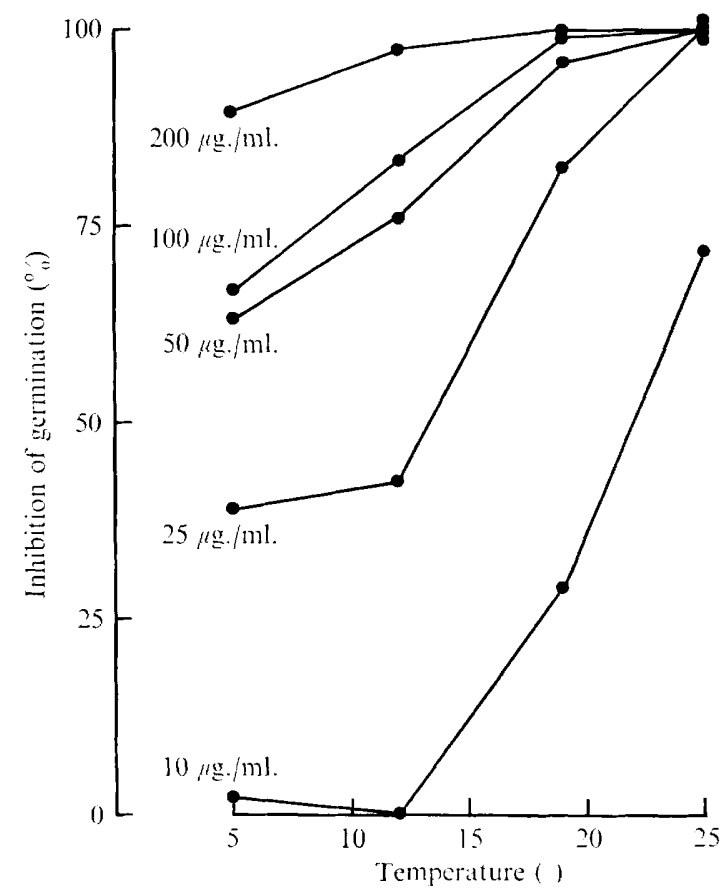

Fig. 8. The effect of temperature on toxicity of streptomycin to sporangia of Pseudoperonospora humuli. Density of the suspension: $10^{5}$ sporangia $/ \mathrm{ml}$; incubation: $20 \mathrm{~h}$. \% germination in water controls was $9 \mathrm{I} \cdot \mathrm{O}$ at $5^{\circ}, 94^{\circ} \mathrm{O}$ at $\mathrm{I} 2^{\circ}, 95.4$ at $19^{\circ}$ and 73.5 at $25^{\circ}$.

Delay between harvest of sporangia and addition of streptomycin. Samples of suspension were mixed with streptomycin solutions $0,15,30$ and $60 \mathrm{~min}$. after sporangia were harvested. A delay of up to $60 \mathrm{~min}$ between harvest and addition of streptomycin had no significant effect on sensitivity of sporangia to the antibiotic. The time taken to set up normal toxicity experiments was always well within this limit.

Addition of streptomycin to suspensions in which sporangia had already commenced germination was also investigated (Griffin, I969). Streptomycin partially inhibited sporangial germination when added to suspensions (at $2^{\circ}$ ) after a $150 \mathrm{~min}$. delay by which time about $50 \%$ of sporangia had germinated. Even at this late stage it still induced liberation of multiflagellate zoospores.

Incubation temperature. It has already been shown (Fig. 4) that streptomycin was more 
toxic to sporangia of Pseudoperonospora humuli at $18^{\circ}$ than at $12^{\circ}$. In further experiments the effect of temperature was investigated over the range 5 to $25^{\circ}$ (Fig. 8). The inhibition of sporangial germination by streptomycin increased markedly with increase in temperature from 5 to $25^{\circ}$. LD 50 values at $12^{\circ}, 19^{\circ}$ and $25^{\circ}$, read from dosage-response curves (as in Fig. 4), were $28 \cdot 8,14 \cdot \mathrm{I}$ and $8 \cdot \mathrm{I} \mu \mathrm{g}$. streptomycin/ml. respectively. This is believed to be the first report of a direct influence of temperature on sensitivity of fungal spores to streptomycin.

Density of suspension. A suspension of sporangia was adjusted to four different densities and tested against streptomycin in the usual manner. Results are shown in Fig. 9. Sensitivity of sporangia to streptomycin decreased with increase in density of the suspension. LD 50 values at $2.5 \times 10^{4}, 5 \times 10^{4}, 10^{5}$ and $2 \times 10^{5}$ sporangia $/ \mathrm{ml}$. were $7 \cdot 1,16 \cdot 8,19 \cdot 3$ and $22.9 \mu \mathrm{g}$. streptomycin $/ \mathrm{ml}$. respectively.

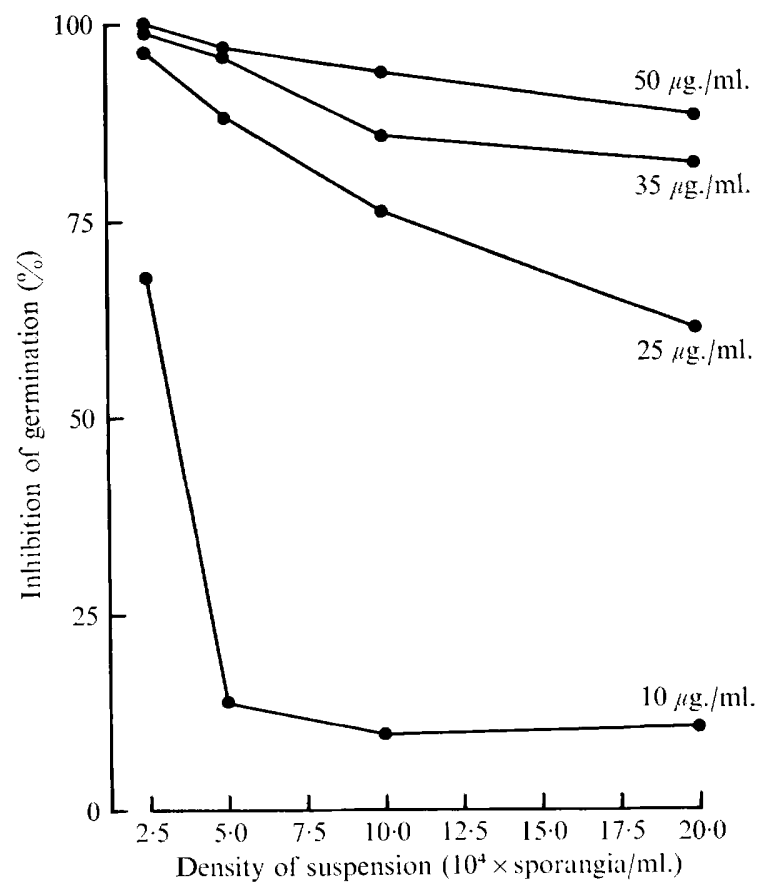

Fig. 9. The effect of density (sporangia/ml.) on toxicity of streptomycin to sporangia of Pseudoperonospora humuli. Incubation: $20 \mathrm{~h}$, at $12^{\circ}$. Percentage germination in the water controls was between $94 \cdot 7$ and $96 \cdot 9$.

Under field conditions it is likely that considerably lower concentrations of sporangia than those used in the previous experiment (Fig. 9) are often exposed to streptomycin. Consequently, a range of antibiotic concentrations was tested against sporangia at densities of $5 \times 10^{3}$ and ${ }_{10} 4 / \mathrm{ml}$. (both at $12^{\circ}$ and $19^{\circ}$ ) and in all cases LD 50 was $<6 \mu \mathrm{g}$. streptomycin/ ml. Thus apart from a reduction in sporulation (Fig. 3) inhibition of sporangial germination could also be a significant factor in the control of hop downy mildew in the field.

Isolates of Pseudoperonospora humuli. It is possible that sporangia from different isolates of Ps. humuli might vary in their sensitivity to streptomycin. Consequently, sporangia from several mass isolates (A, B, C, D and E) were tested. Isolate A was the one normally used in experiments and details of other isolates are given by Griffin (1969). The variation in 
sensitivity to streptomycin of sporangia from the five isolates tested was found to be no greater than the variation which occurred between different batches of isolate $\mathrm{A}$.

Cleanliness of the suspension. Sporangia (isolates B and C) washed directly from naturally infected field shoots were less sensitive to streptomycin than sporangia of the same isolate washed from artificially infected pot plants (Griffin, 1969). However, suspensions washed from field shoots were heavily contaminated with soil particles, nematodes, bacteria, microorganisms and other fungal spores. In contrast, suspensions of sporangia from artificially infected pot plants were relatively clean. It is known that colloidal complexes, such as clay and soil organic matter, adsorb and inactivate streptomycin (Siminoff \& Gottlieb, 195I; Ark \& Wilson, 1956). In addition, streptomycin can be degraded by the soil microflora (Gottlieb, 1952). These factors could certainly account for the reduced toxicity of streptomycin to sporangia washed from field shoots.

Form of antibiotic. Streptomycin sulphate was used in all experiments so far described in contrast to the commerical formulation of streptomycin (Agrimycin 100) used by Ogawa et al. (1960). Consequently, two commercial formulations of streptomycin, Agrimycin I0o (15\% streptomycin, I.5\% oxytetracycline) and Agrimycin I7 (I7\% streptomycin), were assayed against sporangia of Pseudoperonospora humuli and their activity compared with that of streptomycin sulphate. There was no significant difference between the fungicidal activity of streptomycin sulphate and the two commercial formulations of the antibiotic.

The effect of Agrimycin 100 and Agrimycin 17 on duration of zoospore motility was also investigated (Griffin, 1969). Agrimycin 100 was consistently more inhibitory to zoospore motility than were either Agrimycin 17 or streptomycin sulphate; nevertheless, motile periods in Agrimycin 100 were never as short as those reported by Ogawa et al. (1960).

Other readily available salts of streptomycin are the hydrochloride and the hydrochloridecalcium chloride complex. Their fungicidal activity against sporangia of Pseudoperonospora humuli was determined (Griffin, 1969). The hydrochloride was just as toxic to sporangia as the sulphate; however the hydrochloride-calcium chloride complex (a low potency sample) was invariably less toxic to sporangia than were the other two streptomycin salts. Competition between calcium cations and streptomycin cations for binding sites was implicated.

\section{Effects of streptomycin on other fungi}

In addition to the effects of streptomycin on Pseudoperonospora humuli reported here, some activity has also been reported against several other fungi: Pseudoperonospora cubensis (Coe, I955; Ark \& Thompson, 1957), Peronospora tabacina (Grosso, 1954; Anderson, 1956), Peronospora parasitica (Altman \& Davis, 1958), Phytophthora phaseoli (Zaumeyer \& Wester, I956) and Botrytis cinerea (Pelletier \& Hilborn, 1953). On the whole, however, streptomycin has proved ineffective against phytopathogenic fungi other than certain members of the Peronosporales. Since fungicidal activity in vitro of streptomycin against sporangia of $P s$. humuli seemed unusually high, the antibiotic was tested against sporangia of three other members of the Peronosporales, Phytophthora infestans, Plasmopara viticola and Per. parasitica. The results of three separate experiments are presented together in Table 4 . Because $4 \%$ of sporangia of Phy. infestans had lost their cytoplasmic contents in the freshly harvested suspension, apparent levels of 3 to $5 \%$ germination probably represent complete inhibition. Streptomycin was just as toxic to sporangia and zoospores of Phy. infestans as it was to those of Ps. humuli and, similarly, toxicity was dependent on sporangial density (Griffin, 1969). In contrast, both sporangia and zoospores of Plas. viticola were consistently less sensitive to streptomycin than were those of Ps. humuli. Although sporangial concentration was low $\left(2.5 \times 10^{4} / \mathrm{ml}\right.$.) there was $17 \%$ germination in 
$200 \mu \mathrm{g}$. streptomycin $/ \mathrm{ml}$; ; under simila1 conditions germination of sporangia of Ps. humuli would have been completely inhibited by $<50 \mu \mathrm{g} . / \mathrm{ml}$. Streptomycin, as with sporangia of $P s$. humuli, caused an increase in the proportion of multiflagellate zoospores emerging from sporangia of both Phy. infestans and Plas. viticola. This effect was particularly marked with Plas. viticola where $>90 \%$ of zoospores were multiflagellate in 100 and $200 \mu \mathrm{g}$. streptomycin $/ \mathrm{ml}$. Sporangia of Per. parasitica, in contrast to those of the other three fungi tested, germinate directly by producing a single germ tube and both $\%$ germination and the length of 50 germ tubes was recorded (Table 4). Up to $50 \mu \mathrm{g}$. antibiotic/ml. had little effect on either germination or germ-tube extension. $100 \mu \mathrm{g} . / \mathrm{ml}$. reduced both germination and germ-tube extension, and $200 \mu \mathrm{g} . / \mathrm{ml}$. completely inhibited germination.

Table 4. Effect of streptomycin on sporangial germination of Phytophthora infestans, Plasmopara viticola and Peronospora parasitica

Figures in parentheses indicate mean germ-tube length $(\mu \mathrm{m}$.): density of suspensions (sporangia $/ \mathrm{ml}$.) and conditions of incubation; Phy. infestans, $10^{5}, 6$ h. at $12^{\circ}$; Plas. viticola, $2.5 \times 10^{4}, 20$ h. at $12^{\circ}$; Per. parasitica, $3.85 \times 10^{4}, 24$ h. at $18^{\circ}$.

Streptomycin
$(\mu \mathrm{g} . / \mathrm{ml}$.
0
25
50
100
200

$\begin{array}{ccc}\text { Phy. infestans } & \text { Plas viticola } & \text { Per. parasitica } \\ 75^{*} & 83^{*} & 87(430) \\ 29 & 8 \mathrm{I}^{*} & 80(425) \\ 6 & 56^{*} & 84(433) \\ 5 & 42 & 4 \mathrm{I}(67) \\ 4 & 17 & 0\end{array}$

As far as the authors are aware, this is the first report of a direct fungicidal effect of streptomycin on sporangia of Phytophthora infestans, Plasmopara viticola and Peronospora parasitica. Müller, Mackay \& Friend (I954), Zaumeyer \& Doolittle (I956) and Crosse, McWilliam, Rhodes \& Dunn (I960) reported protective effects of streptomycin against infection and spread of Phy. infestans in potato and tomato plants. Antifungal activity of streptomycin against potato blight in vivo has mainly been attributed to an effect on host metabolism rather than to a direct effect on the pathogen (Müller et al. I954; Vörös, Kiraly \& Farkas, 1957; Crosse et al. 1960). However, data presented in this paper and also by Vörös (1963) suggest that a direct effect of streptomycin on Phy. infestans may also play a part in disease control.

\section{DISCUSSION}

It is clear from the work described in this paper and by Horner (I963) that streptomycin exerts its controlling effect on hop downy mildew in several distinct ways. Horner demonstrated that the antibiotic had both protectant and eradicant properties and the work here has shown marked effects on sporulation and sporangial germination. Epiphytotics of downy mildew are initiated by sporangia from primary systemically infected shoots. Sporangia from these shoots bring about secondary infections which in turn initiate others; in this manner the inoculum level can increase rapidly under suitable climatic conditions (Royle, 1970). However, two applications of streptomycin reduced sporulation on primary systemically infected shoots to $27.3 \%$ of that on the untreated controls. Such a reduction in sporulation would markedly decrease the inoculum potential of Pseudoperonospora humuli. The authors consider that, in the British Isles, the reduced sporulation accounts for the main controlling effect of streptomycin.

Reports by Maier (I959) and Coley-Smith \& Beard (I96I) indicated that infectivity of sporangia produced on streptomycin-sprayed shoots was considerably reduced. The work 
described in this paper suggests that sporangia and zoospores of Pseudoperonospora humuli on streptomycin-sprayed foliage could be subjected to inhibitory concentrations of antibiotic. However, there may be a considerable difference between activity of streptomycin on a glass slide and on the surface of a hop leaf. Horner (1963) and Coley-Smith \& Royle (I965) have reported that streptomycin exerted protectant and eradicant properties against Ps. humuli and it seems likely that even if zoospores germinate on sprayed foliage infection may not necessarily result. Considering the work presented in this paper and that of other workers, it appears that streptomycin affects all stages of the infection process. The fact that two sprays of streptomycin virtually eliminated secondary infections even when diseased shoots were left on plants for three weeks (Coley-Smith, 1966) supports this view.

The toxicity of streptomycin to sporangia of Pseudoperonospora humuli in vitro increased markedly with increase in incubation temperature. The implications of this phenomenon in the field are not known. However, if the effectiveness of streptomycin in reducing sporulation of Ps. humuli was similarly influenced by temperature then climatic conditions could seriously influence the efficiency of the antibiotic in controlling the disease.

Toxicity of streptomycin to sporangia of Pseudoperonospora humuli, despite some variation between different batches of the sporangia, was invariably high. Although sporangial suspensions from artificially infected pot plants were relatively clean compared with those from naturally infected field plants, variation in the leaf microflora must have occurred and almost certainly contributed to the small variation in the reaction of different batches of sporangia. Attempts to eliminate this variation by producing sporangia under aseptic conditions failed (Griffin \& Coley-Smith, 1968). Even though heavy contamination of suspensions from field material markedly reduced toxicity of streptomycin it was still considerably higher than reported by Ogawa et al. (I960). Since sporangia from different isolates of Ps. humuli were equally sensitive to streptomycin, the results of Ogawa and his co-workers would appear to be exceptional.

The effect of streptomycin on bacteria appears to involve inhibition of protein synthesis (Dubin, Hancock \& Davis, 1963; Davies, Gorini \& Davis, 1965). Although it has been shown in this paper and by Vörös ( 1965 ) that many Oomycetes are sensitive to streptomycin, the mode of action of the antibiotic against these fungi has not been established. However, Venis (I 969) demonstrated a correlation between antifungal activity of certain diguanidine compounds (including streptomycin) and their ability to inhibit protein synthesis in pea stem segments. Antifungal activity of streptomycin against sporangia of Pseudoperonospora humuli, Phytophthora infestans, Peronospora parasitica and Plasmopara viticola might also be due to an inhibition of protein synthesis, though no direct evidence for this has yet been obtained.

The action of streptomycin on sporangia of Pseudoperonospora humuli was clearly divisible into three sorts. I. Subinhibitory concentrations of antibiotic interfered with cleavage of sporangial cytoplasm but did not prevent germination; consequently multiflagellate zoospores were liberated. This occurred also with Phytophthora infestans and Plasmopara viticola. It seems likely, therefore, that streptomycin interfered with some stage of the cleavage process common to all three fungi. Although cleavage of sporangial cytoplasm into zoospore initials may not involve net protein synthesis, it almost certainly involves biochemical reorganization of existing protein. Disruption of protein synthesis at this stage might account for the failure or part-failure of cytoplasmic cleavage. 2 . Under certain conditions streptomycin inhibited both cleavage and germination without causing any apparent cytoplasmic damage. It is possible that in such instances streptomycin was fungistatic. 3. Inhibition of sporangial germination was mostly followed by a complete 
breakdown of cytoplasm, and in these instances the action of streptomycin was undoubtedly fungicidal.

The liberation of multiflagellate zoospores induced by streptomycin is a phenomenon not previously reported. Although there have been many reports of a small percentage of naturally occurring multiflagellate zoospores in members of the Oomycetes there are few instances in which their existence has been ascribed to any particular substance. Shaw \& Elliot (I968) noted that when $30 \mu \mathrm{g}$. cholesterol $/ \mathrm{ml}$. was included in a presporulation medium for Phytophthora cactorum, multiflagellate and multinucleate zoospores were obtained. Normally, cytoplasmic cleavage in sporangia of Pseudoperonospora humuli is concurrent with papilla degradation. In certain cases streptomycin suppressed cleavage but had no effect on papilla degradation, resulting in the release of a single multiflagellate zoospore. It was concluded, therefore, that the processes of papilla degradation and cytoplasmic cleavage were independent of one another. Similar conclusions were reached for sporangia of Phytophthora erythroseptica and Phytophthora infestans (Vujičić \& Colhoun, 1966; King, Colhoun \& Butler, I968).

The life-span of zoospores can be divided into three phases: motility, encystment and germ-tube growth. The encystment phase was most sensitive to streptomycin. During encystment it is likely that biochemical changes occur in the limiting zoospore membrane. It is possible that streptomycin interfered with these changes, resulting in a less stable cyst membrane and subsequent lysis. Maier (I959) reported that zoospores derived from sporangia from streptomycin-treated shoots were less vigorous and viable than those from normal sporangia.

The marked effect of temperature on toxicity of streptomycin to sporangia of Pseudoperonospora humuli indicates the existence of an active phase of antibiotic uptake.

The authors thank Mr P. E. Smith and Mr R. Wheeler-Osman for assistance with the photography and Pfizer Limited, Sandwich, Kent, for donating streptomycin sulphate and Agrimycin 100. Financial support for one of us (M.J.G.) was provided by the Science Research Council. Much of the work in this paper was incorporated in a thesis (by M.J.G.) for the degree of Ph.D. at the University of Hull.

\section{REFERENCES}

Altman, J. \& Davis, B. H. (I958). Experiments on the control of downy mildew of broccoli and bacterial spot of lima bean with streptomycin. Plant Disease Reporter 42, 416-419.

Anderson, P. J. (1956). Streptomycin for control of blue mould and bed rot of tobacco. Phytopathology 46, 240.

Ark, P. A. \& Thompson, J. B. (1957). Control of downy mildew of cucumber with antibiotics. Plant Disease Reporter 4I, 452-454.

Ark, P. A. \& Wilson, E. M. (I956). Movement of streptomycin into plant tissues from streptomycinpyrophyllite formulations. Phytopathology 46, 634 .

BuIss, C. I. (1935). The calculation of the dosage-mortality curve. Annals of Applied Biology 22, I34-I67.

BoyD, R. E. (1968). Mutational studies on Phytophthora infestans (Mont.) de Bary. Ph.D. Thesis, University of Hull.

Clarke, D. D. (1966). Factors affecting the development of single zoospore colonies of Phytophthora infestans. Transactions of the British Mycological Society 49, 177-184.

COE, D. M. (I955). Streptomycin as a control for downy mildew of cucurbits. Plant Disease Reporter 39 , $729-730$.

Coley-Smith, J. R. (1966). Early-season control of hop downy mildew, Pseudoperonospora humuli (Miy. \& Tak.) Wilson, with streptomycin and protectant fungicides in severely infected plantings. Annals of Applied Biology 57, I 83-191. 
Coley-Smith, J. R. \& Beard, F. H. (I96I). Pathology Section. Review of the year's work. In Wye College Department of Hop Research Annual Report for 1960, pp. 23-25.

Coley-Smith, J. R. \& Royle, D. J. (1965). Pathology Section. Ten year review. In Wye College Department of Hop Research Annual Report for 1964, pp. 66-72.

Crosse, R., McWilliam, R., Rhodes, A. \& Dunn, A. T. (1960). Antifungal action of streptomycin-copper chelate against Phytophthora infestans on tomato (Lycopersicon esculentum). Annals of Applied Biology $48,270-278$.

Cruickshank, I. A. M. \& Mueller, K. O. (1957). Water-relations and sporulation of Peronospora tabacina Adam. Nature, London $\mathbf{1 8 0}, 44-45$.

Davies, J., Gorini, L. \& Davis, B. D. (I965). Misreading of RNA codewords induced by aminoglycoside antibiotics. Molecular Pharmacology 1, 93-106.

Dubin, D. T., Hancock, R. \& Davis, B. D. (1963). The sequence of some effects of streptomycin in Escherichia coli. Biochimica et biophysica acta 74, 476-489.

GarretT, R. G. \& Tomlinson, J. A. (1967). Isolate differences in Olpidium brassicae. Transactions of the British Mycological Society 5o, 429-435.

Gottlieb, D. (1952). Disappearance of antibiotics from soil. Phytopathology 42, 9.

Griffin, M. J. (1969). Some effects of streptomycin on sporangia of Pseudoperonospora humuli (Miy. \& Tak.) Wilson. Ph.D. Thesis, University of Hull.

Griffin, M. J. \& Coley-Smith, J. R. (1968). The establishment of hop tissue cultures and their infection by downy mildew Pseudoperonospora humuli (Miy. \& Tak.) Wilson under aseptic conditions. Journal of General Microbiology 53, 231-236.

Grosso, J. J. (I954). Control of tobacco blue mold by antibiotics. Plant Disease Reporter 38, 333.

Ho, H. H. \& Hickman, C. J. (I967). Asexual reproduction and behaviour of zoospores of Phytophthora megasperma var. sojae. Canadian Journal of Botany 45, 1963-1981.

HoRner, C. E. (1963). Chemotherapeutic effects of streptomycin on establishment and progression of systemic downy mildew infection in hops. Phytopathology 53, 472-474.

Horner, C. E. \& MaIer, C. R. (I957). Antibiotics eliminate systemic downy mildew from hops. Phytopathology 47, 525 .

King, J. E., Colhoun, J. \& Butler, R. D. (i968). Changes in the ultrastructure of sporangia of Phytophthora infestans associated with indirect germination and ageing. Transactions of the British Mycological Society 5I, 269-281.

Kole, A. P. (1955). Some observations on the zoospores from the zoosporangia of Plasmodiophora brassicae Woron. Tijdschrift over Plantenziekten 61, I59-162.

McLean, R. C. \& CoOK, W. R. I. (I952). Plant Science Formulae. London: Macmillan.

MAIER, C. R. (1959). Effects of streptomycin sulphate on the hop downy mildew fungus in vivo. Phytopathology 49, 545 .

MAIER, C. R. (I960). Streptomycin absorption, translocation, and retention in hops. Phytopathology 50, $35 \mathrm{I}-356$.

Müller, K. O., Mackay, J. H. \& Friend, J. N. (I954). Effect of streptomycin on the host-pathogen relationship of a fungal pathogen. Nature, London 174, 878-879.

Ogawa, J. M., McCaIn, A. H. \& Hall, D. M. (1960). Streptomycin absorption in diseased and healthy hop tissues and its effect on the hop downy mildew organism and mildew development. Phytopathology 50, 278-280.

Pelletier, E. N. \& Hilborn, M. T. (1953). Blossom and twig-blight of low-bush blueberry. Phytopathology $43,48 \mathrm{I}$.

RoYle, D. J. (1970). Infection periods in relation to the natural development of hop downy mildew (Pseudoperonospora humuli). Annals of Applied Biology 66, 281-291.

SCHICKe, P. (I96I). Beobachtungen zur systemischen Fungizidwirkung von Streptomycin. Mededelingen van de Landbouwhoogeschool en de Opzoekingsstations van de Staat te Gent 26, I370-1 377.

Shaw, D. S. \& Elliot, C. G. (1968). Streptomycin resistance and morphological variation in Phytophthora cactorum. Journal of General Microbiology 51, 75-84.

Siminoff, P. \& Gottlieb, D. (195I). The production and role of antibiotics in the soil. I. The fate of streptomycin. Phytopathology 4I, 420-430.

VENIS, M. A. (1969). Similarities in action between streptomycin and hordatine, an antifungal factor in barley. Phytochemistry 8, I 193-1197.

Vörös, J. (1963). Mode of action of selective fungistatic effect of streptomycin. Nature, London r99, I 1 10I I I I. 
Vörös, J. (1965). Streptomycin sensitivity of Oomycetes due to the increased absorption of streptomycin by their mycelia. Phytopathologische Zeitschrift 54, 249-257.

VÖRÖS, J., KIRALY, Z. \& FARKAS, G. L. (1957). Role of polyphenolase in streptomycin-induced resistance to Phytophthora in potato. Science, New York 126, 1 I 78.

Vujičıć, R. \& Colmoun, J. (1966). Asexual reproduction in Phytophthora erythroseptica. Transactions of the British Mycological Society 49, 245-254.

Wilcoxon, F. \& MCCAllan, S. E. A. (1939). Theoretical principles underlying laboratory toxicity tests of fungicides. Contributions. Boyce Thompson Institute for Plant Research ro, 329-338.

Zaumeyer, W. J. \& Doolittle, S. P. (1956). Control of late blight on tomato with streptomycin. Phytopathology 46, 32 .

ZAUimeYer, W. J. \& WeSter, R. E. (1956). Control of downy mildew of lima beans with streptomycin. Phytopathology 46, 32. 